\title{
Characterization of Computerized Tomographic findings In Traumatic head Injured PatientsIn Jos, North Central,Nigeria.
}

\author{
U O Ulu ${ }^{1}$, J E Ekedigwe ${ }^{2}$ \\ ${ }^{l}$ Department of Radiology, Jos University Teaching Hospital, PMB 2076,Jos ,Plateau State- Nigeria \\ ${ }^{2}$ Department of Radiology, Jos University Teaching Hospital PMB 2076,Jos ,Plateau State- Nigeria.
}

\begin{abstract}
:
Background:Head traumais a major health problem which is becoming increasingly a burden on the already stressed accident and emergency services of hospitals in Nigeria especially in the Northcentral part of Nigeria due to heightened insurgent activities. It is associated with significant long term morbidity and mortality.

The aim of the study was to characterize and establish patternof computed tomographic features in patients with head trauma in Jos metropolis.

Methods: We prospectively evaluated CT findings in 110 patients between the ages of one and eighty years who were sent to the Radiology department of JUTH for CTbrain with history of head trauma.

Results: There were 81 males and 29 females with a mean age of 33.4years (SD26.5).Cerebral contusion, fractures, and Intracranial haemorrhage, were the commonest CT features in subjects and accounted for $21.8 \%$ , 19.3\%and13.7.8\%, for cerebral contusion, fractures and intracranial haemorrhage respectively. The age ranges of 21 to 40 years were mostly affected accounting for $45.4 \%$ of cases with $37.3 \%$ male subjects. $16.4 \%$ of the subjects were children under the age of ten.

Conclusions: this study has clearly demonstratedthat cerebral contusion, intracranial haemorrhage and fracture are the commonest computed tomographic features seen in this region among head injured patients and these involve men mostly in their reproductive and sexually active ages.
\end{abstract}

Key Words: Computerized tomography (CT), Magnetic resonance imaging (MRI) Head trauma,Findings, Incidence,Jos. Northeast

\section{Introduction}

Head trauma refers to head injuries to the brain and other parts of the head such as the skull and scalp [1].Head injury is the most common cause of death in trauma victims, accounting for approximately fifty percent of death at the accident site.[2,3].

Complications from close head injuries are the largest cause of mortality and morbidity in patients who reach the hospital alive. Of particular importance are motorcycle accidents involving unhelmented passengers which produce severe injuries and injuries from fast moving objects $[4,5]$.

Traumatic injury to the brain involves a primary brain injury at impact and leads to disruption of brain substance and blood vessels; it can be classified based on the severity and mechanism (close and penetrating head injuries)or other features e.g occurring in a specific location or over wide spread area[6,7].

About $8 \%$ of all the cases sent to the radiology department of Jos university teaching Hospital for various radiological investigations are from the accident and emergency unit and $49 \%$ of these cases involve trauma to the head and require CT scan[12].

Computed tomography is the primary imaging modality for the initial diagnosis and management of head injured patients, because it is safe and can be performed on serious injured patients, furthermore, it offers rapidity of scanning and maneuverability, with the brain being the most widely imaged .Computed tomography is less sensitive to patient motion during examination, because imaging can be performed much more rapidly when compared to magnetic resonance imaging $[8,9]$.

Due to rapid increase in motorized vehicular accidents, and frequent hostilities in this region, head injury is increasing every day, and this has posed a serious problem on the accident and emergency unit[10,11].Therefore, there is need to establish for a data base showing the pattern and features seen in computed tomography in head trauma. This will help in proper management of patients with head trauma; and also useful forfurther research in this area..

\section{Material And Methods}

This study was carried out in the radiology department of Jos university teaching hospital (JUTH), North East, Nigeria.JUTH is a tertiary institution that receives referral from the neighboring secondary and tertiary health institutions for computerized tomographic scans. 
We prospectively evaluated 110 subjectsto characterize computed tomographic features in head trauma to establish incidence and pattern of presentation. Subjects were referred from the accident and emergency unit of Jos university teaching hospital and other referral health facilities in Jos metropolis and the study was conducted between November 2009 and October 2010. Thesubjects for the study consisted of 81males (73.6\%) and 29 females $(26.4 \%)$ with ages ranged between one year and eighty years.

A Bright speed 4 slice helical CT scanner was used to acquire the images for the study. Non contrast axial slices were taken from the base of the skull to the vertex at $5 \mathrm{~mm}$ intervals and post processing of images involving reconstructions were done where necessary. All results were interpreted by consultant Radiologists. The vault showing discontinuity or fragments, regions ofhyperdensity and hypodensity were considered significant. The ventricles, basal cisterns and midline structureswere assessed for symmetry and orientations.

The significant regions or features were categorized into fractures,subdural haemorrhage,epidural haemorrhage, intracerebralcontusion, eodema, soft tissue swelling and normal.

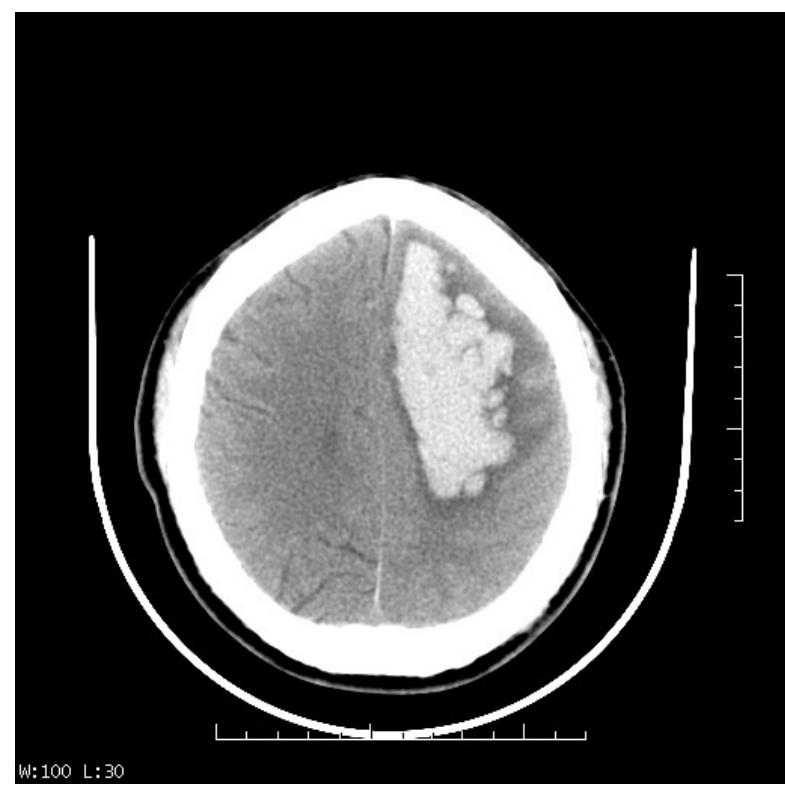

Figure 1: Computerized axialTomographic brain of a 36 year-old male with history of acute mild head injury. $\mathrm{Ct}$ findings show moderateleft intracranialhaemorrhage with edema.

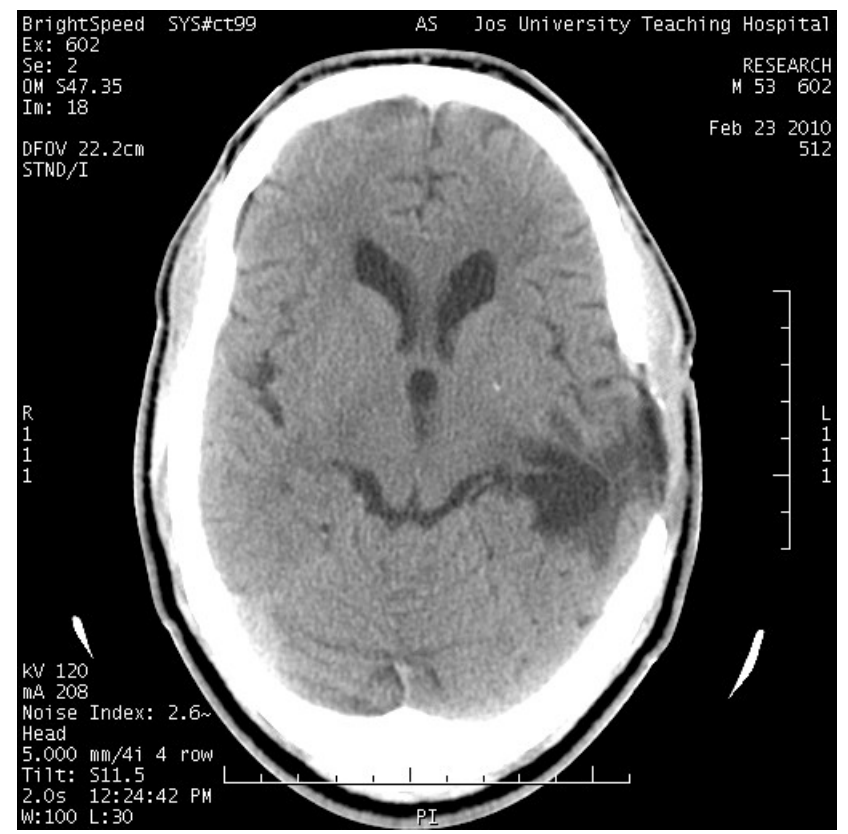

Figure 2 shows the computed axial tomographic brain image of a 52 year-old man with acute head injury. CT findings showleft brain contusion and skull fracture with loss of bone. 


\section{Data Analysis}

Descriptive statistics was used for the analysis. The age and gender distribution was determined by frequency counts and the mean age calculated. The frequencies of the CT features seen were categorized according to age and gender.

\section{Results:}

Table 1: GENDER AND AGE DISTRIBUTION OF SUBJECTS

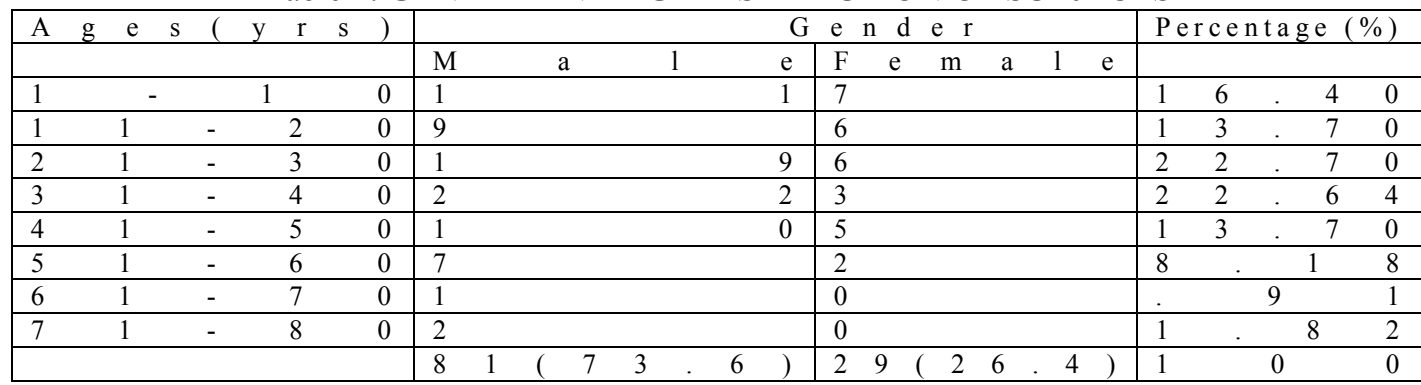

Table 1 show the age and gender distributions of subjects with the males accounting for $73.6 \%$ of study subjects, with the age range of 21 to 40 being the majority ( 50 subjects).

A total of 110 subjects whose request indicated head injury or trauma during this period fulfilled the study criteria. The subjects comprised of 81 males and 29 females between the ages of one to eighty with a mean of 33.4years ( $\mathrm{SD}=26.5$ years).

Table 2: Incidence And Pattern Of Ct Findings Of Subjects.

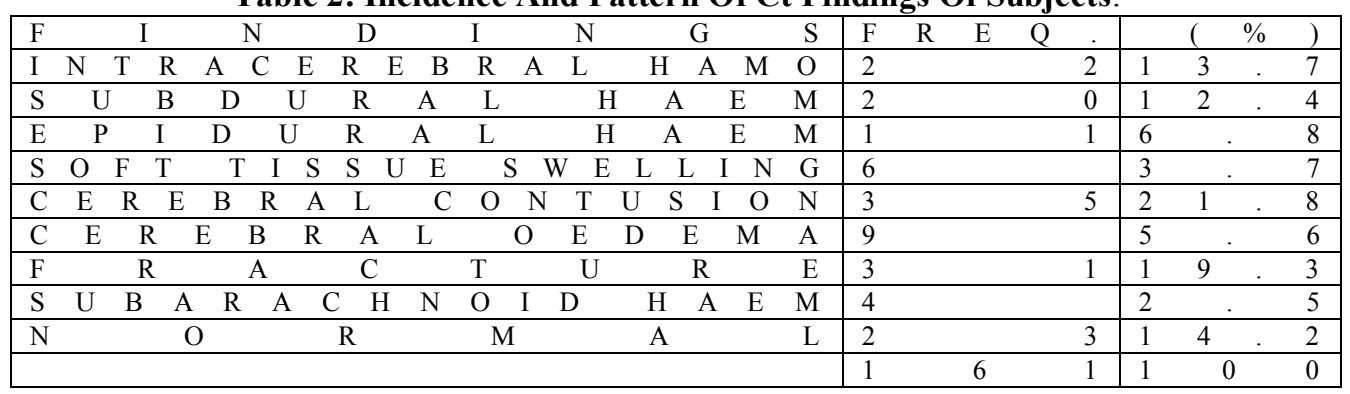

Table 2 shows the incidence and pattern of CT features of subjects. The commonest feature seen was cerebral contusion with an incidence of $21.8 \%$ Bone fracture accounted for $19.3 \%$ of the cases. Intracerebral hemorrhage and subdural hemorrhage were found in 22(17.7\%), and 20(12.4) subjects respectively.

Result further showed that 9 patients (5.6\%) had cerebral eodema, 2.5\%had subarachnoid hemorrhage ,epidural collection were send in $6.8 \%$ of subjects, $5.6 \%$ of the subjects showed features of soft tissue swelling while $14.2 \%$ of the cases were normal.

Table 3: Sex Distribution Of Ct Features In Subjects

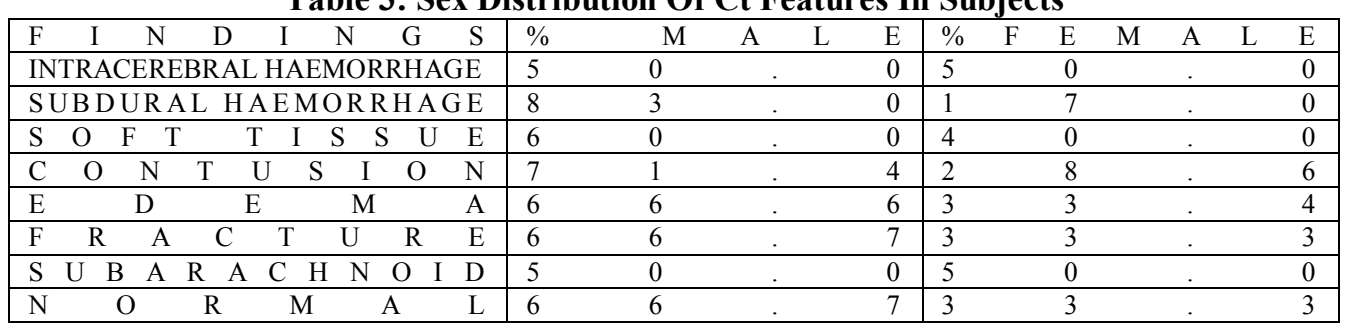

Table 3 shows the sex distribution of CT features in subjects. Summary of the result showsthat more than $60 \%$ of cases occurred in male subjects except in intracranialhaemorrhage and subarachnoid arachnoidhaemorrhage where therewas a one to one ratio in features.

\section{Discussion:}

The choice of radiological investigations in head trauma in Africa is influenced by factors such as cost and accessibility of equipment [8] Conventional radiography is usually the first line of investigation of the skull in head trauma because it is cheap and available in most hospitals in this environment, however, it lacks the 
ability to characterize lesions in the brain. Computed tomography offers rapidity of scanning and maneuverability and able to give bone details, however, computed tomography is less sensitive to patient motion during examination $[9,10]$.

Most patients who presented to the department of Radiology in the acute phase of head trauma had CT done .And this was found to be very rewarding; in most cases diagnosis was reached after the CT. Our studyrecords a $85.8 \%$ positive CT findings, this was similar to a study conducted at Enugu, South east Nigeria which recorded $80.1 \%$ pathological findings and $19.9 \%$ normal findings. This figure was however, higher than the incidence recorded in a similar study in Brazil and Massachusset, USA where the rates were $39.25 \%$ and $21 \%$ respectively $[10,11]$.This high incidence of positive results could be partly attributed to the high level of aggression and restiveness which includes firearm injuries, automobiles and assaults prevalent in the locality. With a normal CT finding of $14.2 \%$ recorded in the study another author reported a variable incidence of normal CT scan range of $10-44 \%$. The variability was attributed to the time between scan and trauma including variability in the definition of normal scan in the studies [9]. It was reported in two series that severely head injured patients with normal initial CT scans never developed intracranial hypertension.[10] However, literatures have shown that $50 \%$ of subjects eventually proven to have diffused axonal injury demonstrate a normal CT upon presentation especially in an unconscious patient with critical Glasgow coma scale scores [13].It is also conceivable that methodological differences among studies may again account for differences observable.

Regarding lesion types, Cerebral contusion was seen in $21.8 \%$.of our subjects, which was lower in incidence than two other reports which showed a $25 \%$ to $26 \%$ incidence rates [14,15].Again, these reports only included patients with loss of consciousness or amnesia, therefore selecting patients at higher risk of intracranial injuries which may have accounted for the difference.

Skull fractures accounted for $19.3 \%$ of subjects. In other reports, the rates were much lower $(14.3 \%, 8.5 \%$ and 4.1\%). But, Shackford et al, 1992, also observed an incidence rate of $19.3 \%$ of skull fractures, similar to our study. $[16,17,18,19]$

Intracerebral hemorrhage after head trauma is a frequent cause of death and disability. Expeditious evaluation and adequate management of patients who initially seem at low risk are the most important factors to reduce their mortality [20]. We recorded a $17.7 \%$ incidence of intracerebral hemorrhage. One study recorded a $10.4 \%$ incidence lower than ours though the researcher excluded patients younger than 18 years in his work, this probably explains the difference in incidence[ 21].

Male subjects were mostly involved in this study between the ages of 21 and 40 years. This is most probably due to the fact that vehicular driving is still a male dominated activity in this part of the world and the frequent hostility common in this region are mostly involve men.

\section{Conclusion.}

In conclusion, our study have shown that fractures, intracranial haehorrhage and cerebral contusion are the commonest findings in computed tomography among head injured patients in this region especially among men in their reproductive and sexually active ages, with intracerebral contusion having the highest incidence.These findings will help neurologists in the management of this group of patients.

\section{Acknowledgement}

The researchers are grateful to members and staff of Radiology department for their encouragement

\section{References}

[1] Lazar J.G. head injury, surgery-principles and practice, $3^{\text {rd }}$ edition, Lippincott and William2001;295

[2] Davis p.,LavitaA.,Farina M.L., VecahG.Prognosis of severe head injuries. Journal of Neurosurgery2010;57:779-783

[3] Heegaard WG, Biros MH. Head. In: Marx J. Rosen's Emergency Medicine: Concepts and Clinical Practice. 6th ed. St. Louis, Mo: Mosby; 2006: chap. 38.

[4] Selwyn taylor, head injury,surgical management. William Heinemann medical books ltd,London:745

[5] Anderson T, Heitger M, Macleod A.D ."Concussion and Mild Head Injury".Practical Neurology 2006; 6: 342-357. Retrieved 200801-23.

[6] McCaffrey RJ "Special Issues in the Evaluation of Mild Traumatic Brain Injury". The Practice of Forensic Neuropsychology1997: Meeting Challenges in the Courtroom. New York: Plenum Press. pp. 71-75.

[7] National Safe Kids Campaign (NSKC) (2004). "Bicycle injury fact sheet" .Retrieved 2006-12-19.

[8] Ohaegbulam et al.,2011. Cranial computed tomography scan finding in head trauma patients in Enugu,Nigeria.Surgical neurology international:2;182.

[9] Dowine A 2007.Tutorial CT in head trauma.Available at http:/www.redilogy.co.ukisr-tutorial/trauma.Acessed on the 18/2/2010

[10] NyamePK,Jumah KB ,Adjei S . Computed Tomography scan of the brain in the evaluation of stroke in Ghanians. East African medicaljournal, 2006;75(11):637-63.

[11] UdigriN.R.,TewanM.K.,DwarakanattS.,Khandel N .Role of computed tomography in minor head injury. The Indian journal of neurotrauma. 2004; vol 1;33-36.

[12] Small, Gary W ."What we need to know about age related memory loss".British Medical Journal2002; 324: 1502-1507. . Retrieved 2008-11-13. 
[13] Atabaki SM. Pediatric head injury.Pediatr Rev. 2007 Jun;28(6):215-24..

[14] Stein SC, Ross SE. Mild head injury: a plea for routine early CT scanning. J Trauma 1992;33:11-13.

[15] Jeret JS, Mandell M, Anziska B, et al. Clinical predictors of abnormality disclosed by computed tomography after mild head trauma. Neurosurgery 1993;32:9-16.

[16] Schackford SR, Wald SL, Ross SE, et al. The clinical utility of computed tomographic scanning and neurologic examination in the management of patients with minor head injuries. J Trauma 1992;33:385-394.

[17] McCrea, M. (2007). Mild Traumatic Brain Injury and Postconcussion Syndrome: The New Evidence Base for Diagnosis and Treatment (American Academy of Clinical Neuropsychology Workshop Series). New York: Oxford University Press.

[18] Sauaia A, Moore FA, Moore EE, et al. (February 1995). "Epidemiology of trauma deaths: A reassessment". The Journal of Trauma38 (2): 185-93.

[19] Cummings, J.L. (1993). "Frontal-subcortical circuits and human behavior.". Archives of Neurology50 (8): 873-880.

[20] Klauber MR, Marshall LF, Luerssen TG, et al. Determinants of head injury mortality: importance of the low risk patient. J Neurosurg 1989;24:31-36.

[21] Bordignon K C,Oleschko W A.CT scan findings in mild head injury.Arqneuropsiquiatr 2002,60(2-A):204-210 